\title{
Indigenous arbuscular mycorrhiza and Trichoderma from systems with soybean predominance can improve tomato growth
}

\author{
Jacqueline Giselle Commatteo ${ }^{1}$, Verónica Fabiana Consolo ${ }^{2}$, Pablo Andrés Barbieri ${ }^{3,4}$ \\ and Fernanda Covacevich ${ }^{2,3 *}$ \\ ${ }^{1}$ Agencia Nacional de Promoción Científica y Técnica- Instituto Nacional de Tecnología Agropecuaria, \\ Balcarce, Argentina. \\ ${ }^{2}$ Instituto de Biodiversidad y Biotecnología, Consejo Nacional de Investigaciones Científicas y Técnicas-Fundación \\ para las Investigaciones Biológicas Aplicadas Mar del Plata, Argentina. \\ ${ }^{3}$ Unidad Integrada Balcarce, Argentina. \\ ${ }^{4}$ Consejo Nacional de Investigaciones Científicas y Técnicas Balcarce, Argentina.
}

[Received: April 3, 2019 Accepted: June 21, 2019]

\section{Abstract}

In the last decades, there has been a tendency towards sustainable agriculture. Following this trend, edaphic fungi as Trichoderma and arbuscular mycorrhizal fungi (AMF) could increase plant growth contributing to diminish agricultural chemical supply. However, little information exists in current research regarding the possible effects of alternative practices to soybean monoculture systems on fungal groups that could contribute to plant health and/or productivity. Thus, our objective was to assess changes in the abundance and diversity of indigenous AMF and Trichoderma from a long-term field experiment located in the Argentinean Pampas, in order to test the effect of alternative practices to soybean monoculture. The fungal ability to promote the growth of crops, such us tomato plant was also tested. Soil samples were collected from a soybean monoculture system (Sb), a system including cover crop (Avena sativa) followed by soybean (CC/Sb) and a system including rotations (rot) of SoybeanMaize-Wheat crops CC/Sb-rot, M-rot and W-rot, respectively. Highest AMF and Trichoderma abundance was found at $W$-rot and M-rot systems, and highest AMF diversity was found at $W$-rot and CC systems. Furthermore, highest mycorrhizal colonization was found at CC/Sb and W-rot systems. Inoculated plants with single AMF consortium or with Trichoderma strains showed significant increases in comparison with the control. Dual inoculation increased tomato plant growth as compared to the control, and evidence of synergism was found by increases in shoot and root growth. Our results show that dual inoculation with indigenous AMF and Trichoderma from alternative crop systems to soybean monoculture could play an important role in tomato plant growth. This information could be useful to decrease production costs and environmental impacts.

Keywords: Inoculation, mycorrhizal colonization, trichoderma, cover crops, crop rotation systems

\section{Introduction}

The global current need for food production has put pressure on increasing yields; consequently, agriculture has become more competitive and efficient (Cho et al., 2004). In Argentina, the main change in agricultural production has been the expansion of soybean cultivation as monoculture (Solbrig, 2005). This includes the permanent application of chemicals and little residue incorporation, which leads to a decrease in soil organic matter (SOM) content. This could affect the microbial biodiversity, increase soil degradation, and contribute to environmental deterioration (Marshall et al., 2011).
Abuscular mycorrhizal fungi (AMF), which belong to phylum Glomeromycota, form mutualistic associations with most terrestrial plants (Gupta et al., 2017). The AMF increase the growth of a wide variety of crops (Sharif et al. 2010) as well as the tolerance to biotic and abiotic stress (Sidhoum and Fortas, 2018); it also contributes to soil aggregates stability (Rillig et al., 2002). As a result, in the last decades, the AMF have been highlighted as potential biofertilizers.

In soils, the plant-AMF system is in interaction with other microorganisms as Trichoderma fungi (Tiunov and Scheu, 2005). Trichoderma is widely distributed in different environments, especially in those with high SOM (Harman,

\footnotetext{
*Email: covacevich.fernanda@inta.gob.ar
} 
2006). Among other properties, Trichoderma can solubilize insoluble soil $\mathrm{P}$ compounds and has positive effects on plant growth and pest biocontrol. These properties could result from rapid growth and antagonistic action to plant root pathogens (Guigón-López et al., 2010). For this reason, Trichoderma is also considered a potential bioinoculant which enhances plant growth and health. Therefore, the combination of Trichoderma ( $\mathrm{P}$ solubilizer) and AMF ( $\mathrm{P}$ transporter) consortium could probably increase plant growth and also control fungal pests.

Positive interactions between Trichoderma harzianum and AMF were reported by Martínez-Medina et al. (2011) who registered a reduction of foliar disease produced by Fusarium fungus in melon (Cucumis melo). Due to Trichoderma antifungal properties, antagonism with AMF could be expected. Antagonistic effects of Trichoderma on AMF were found by Santander and Olave (2014) and were related to antifungal metabolite compounds released by Trichoderma. On the other hand, synergistic or neutral effects on potato plants were found by Ene and Alexandru (2008) with different Trichoderma strains ( $T$. longibrachiatum, $T$. virens, and T. koningii) and AMF belonging to the Glomus and Gigaspora genus.

Currently, inoculation with fungi as biofertilizers is not used as a management practice in extensive crops. Cover crops (CC) have been considered as an alternative to increase SOM in soybean monoculture (Villamil et al., 2006). Avena sativa is a commonly used $\mathrm{CC}$, because of the carbon residues it leaves in the soil (Duval, 2016); it also has numerous benefits, such as physical soil protection (Fernández et al., 2007). Another alternative to soybean monoculture that maximizes productivity per unit area by optimizing the use of resources and reducing pest are crop rotations including soybean with other crops (Kumar and Goh, 2000). However, little is known about how these practices could affect the soil microbial structure and or activity. In particular, it is interesting to know if some alternatives to soybean monoculture can affect microbial groups that could fulfill roles in plant health and/or productivity.

We hypothesize that alternative systems to soybean monoculture, such as $\mathrm{CC}$ or crop rotations modify soil microbial abundance and/or diversity. Therefore, there is a greater probability to find combinations of indigenous AMFTrichoderma that could be considered as potential bioinoculants. The present study was conducted to understand the effect of different soybean crop systems on the abundance and/or diversity of indigenous AMF and Trichoderma strains from the Argentinean Pampas and to select AMFTrichoderma consortium with ability to increase plant growth. In addition, we aimed to advance our knowledge of the identity of selected strains of potential biotechnological interest.

\section{Materials and Methods \\ Experimental site and soil samples collection}

The study was carried out in a long-term field trial under no-tillage started in 2006, 11 years before our study, at the Instituto Nacional de Tecnología Agropecuaria (INTA) Research Station at Balcarce, Argentina ( $37^{\circ} 45^{\prime} \mathrm{S}, 58^{\circ} 18^{\prime}$ $\mathrm{W} ; 870 \mathrm{~mm}$ mean annual rainfall; $13.8^{\circ} \mathrm{C}$ mean temperature; $138 \mathrm{~m}$ above sea level). The soil was a Typic Argiudoll (Mar del Plata series, USDA taxonomy), with less than $2 \%$ slope and loam texture at the surface layer $(0-20 \mathrm{~cm})$. The experimental design consisted of a randomized complete block design (RCBD) with three replications per treatment. Three treatments were evaluated: 1) soybean monoculture $(\mathrm{Sb})$; 2) cover crop/soybean (CC/Sb); 3) crop rotation (rot) with the three phases of rotation in different plots (CC/Soybean-Maize-Wheat) with Wheat (W-rot), Maize (Mrot) and $\mathrm{CC} / \mathrm{Sb}(\mathrm{CC} / \mathrm{Sb}$-rot) in the year of study; that resulted in fifteen experimental units of $15 \mathrm{~m} \mathrm{x} 5 \mathrm{~m}$ each.

The $\mathrm{Sb}$ system was maintained without weeds during the fallow period using glyphosate application at the beginning of spring. Soybean (Glycine max) was sown $(0.35 \mathrm{~m}$ row spacing) using a plant density of 450,000 seeds ha-1 inoculated with Bradyrhizobium japonicum (E109 INTA strain, at a rate of $3 \mathrm{~mL} \mathrm{~kg}^{-1}$ of seed; commercial product Nitragin Cell Tech $10^{9}$ bacteria $\mathrm{mL}^{-1}$ ). At sowing, it was fertilized with $20 \mathrm{~kg}$ phosphorus $\mathrm{ha}^{-1}$ as triple superphosphate (0-46-0) and $15 \mathrm{~kg}$ sulfur (S) $\mathrm{ha}^{-1}$ as gypsum $(16 \% \mathrm{~S}, 20 \% \mathrm{Ca}$ (calcium), $\mathrm{SO}_{4} \mathrm{Ca} 2 \mathrm{H}_{2} \mathrm{O}$ ). The $\mathrm{CC}$ used in treatments $\mathrm{CC} / \mathrm{Sb}$ and $\mathrm{CC} / \mathrm{Sb}$ rot was oat (Avena sativa $\mathrm{L}$.), using a density of $120 \mathrm{~kg} \mathrm{ha}^{-1}$ (0.175 m row spacing). The CC was fertilized with $\mathrm{N}$ at tillering (90 $\mathrm{kg} \mathrm{N}^{-1}$ as urea). Cover crop was killed just at flag leaf, with 3-4 $\mathrm{L} \mathrm{ha}^{-1}$ of glyphosate $(48 \%$ active principle). In the $\mathrm{W}$-rot treatment, wheat (Triticum aestivum Buck Sy200) was sown using a density of $140 \mathrm{~kg}$ seeds $\mathrm{ha}^{-1}$ and fertilized with $\mathrm{P}\left(20 \mathrm{~kg} \mathrm{P} \mathrm{ha}{ }^{-1}\right.$ as triple superphosphate). $\mathrm{N}\left(150 \mathrm{~kg} \mathrm{~N} \mathrm{ha}^{-1}\right.$ as urea) and $\mathrm{S}$ (15 kg S ha${ }^{1}$ as gypsum) fertilization were applied at tillering. At wheat harvest, plots were sown with unfertilized soybean. In the Mrot treatment, maize crop (Zea mays, DK72-1-10 RR2) was sown using a density of 80,000 plants $\mathrm{ha}^{-1}(0.52 \mathrm{~m}$ row spacing) and fertilized with $\mathrm{P}\left(20 \mathrm{~kg} \mathrm{P}^{-1}\right.$ as ammonium phosphate $\left.\left(\mathrm{PO}_{4}\left(\mathrm{NH}_{4}\right)_{3}\right)\right)$. $\mathrm{N}$ fertilization was applied as urea at V6 stage (Ritchie and Hanway, 1982). Pests, weeds and diseases were traditionally controlled with chemical methods.

Fifteen composite soil samples, 10 sub-samples per plot, were separately collected in summer (January) by using a cylindrical sampler $5 \mathrm{~cm}$ in diameter, 0-15 cm depth. Subsamples were separately homogenized per treatment and 
replicates were stored in a refrigerator $\left(4^{\circ} \mathrm{C}\right)$ until processed (two days later). Part of the soil samples were used for soil chemical parameters determination, as detailed in Table 1.

\section{Genetic AMF-belonging glomerales diversity assessment}

The genetic diversity of AMF was assessed with an emphasis on the most representative genera of AMF (Glomus and Funneliformis, belonging to the Glomerales order according to Redecker et al. (2013)) by a genotypic fingerprinting approach, using the polymerase chain reaction-Single Stranded Conformation Polymorphism (PCR-SSCP). Soil DNA extraction was performed separately for each field treatment by using the MoBio Power Soil DNA isolation kit, according to the
(2004). The SSCP gels were silver stained according to Benbouza et al. (2006), scanned and finally analyzed. The Shannon-Weaver (1949) diversity H' Index of Glomales was calculated (Van Elsas et al., 2012) based on the SSCP pattern as detailed in Eq. (1):

$$
H^{\prime}=-\sum_{i=1}^{S} \quad P i \ln P i
$$

Where $\mathrm{Pi}=\mathrm{Ni} / \mathrm{N}, \mathrm{Ni}$ is the abundance of the ith ribotype, $\mathrm{N}$ is the total abundance of all ribotypes in the sample (lane of SSCP gels). The abundance of SSCP bands were indicated by the intensity of each SSCP band extracted by the Phoretix 1D PRO software (Nonlinear Dynamics, United Kingdom).

Table 1: Chemical soil characteristics of different plots of field experiment. OM: Organic Matter; P-Bray: available soil phosphorus

\begin{tabular}{llll}
\hline Field plot & $\mathbf{p H}$ & OM (\%) & P-Bray $\left.\mathbf{~} \mathbf{m g ~ k g}^{-\mathbf{1}}\right)$ \\
\hline $\mathrm{Sb}$ & $5.69( \pm 0.2)$ & $5.12( \pm 0.4)$ & $33.37( \pm 1.4)$ \\
$\mathrm{CC} / \mathrm{Sb}$ & $5.63( \pm 0.8)$ & $5.51( \pm 0.8)$ & $28.09( \pm 1.2)$ \\
$\mathrm{M}$-rot & $5.25( \pm 0.6)$ & $5.54( \pm 0.7)$ & $26.01( \pm 0.8)$ \\
W-rot & $5.62( \pm 0.5)$ & $5.48( \pm 0.9)$ & $27.72( \pm 1.1)$ \\
$\mathrm{CC} / \mathrm{Sb}$-rot & $5.46( \pm 0.3)$ & $5.49( \pm 0.5)$ & $30.36( \pm 0.9)$ \\
\hline
\end{tabular}

Values in parentheses corresponding to standard deviations $(n=3)$.

manufacturer's instructions. A nested PCR was performed for amplifying a fragment of the large subunit of ribosomal DNA gene (28S) by a nested PCR. In the first PCR reaction, approximately $700 \mathrm{bp}$ were amplified using the fungal specific primer pair LSU0061/LSU0599 (5'AGCATATCAATAAGCGGAGGA-3' $\%$ 5'TGGTCCGTGTTTCAAGACG-3'). On the second PCR reaction, the products originating from the first PCR reaction (diluted 1:50) were used as template for amplifying an approximately $400 \mathrm{bp}$ fragment, corresponding to the $28 \mathrm{~S}$ rDNA gene of AMF belonging the Glomus/Funneliformis genera (Funneliformis mosseae $=$ Glomus mosseae $;$ F caledonium $=$ Glomus caledonium and F. geosporum = Glomus geosporum) (Van Tuinen et al., 1998). PCR products generated by LSUrk4f and LSUrk7r primer pairs were subsequently analyzed by SSCP using a Dcode Universal Mutation Detection System (Bio-Rad, USA). Five microliters of the PCR product were added to 3 $\mu \mathrm{L}$ of denaturing loading mixture $(95 \%$ deionized formamide, $0,05 \%$ bromophenol blue, $0.05 \%$ xylene cyanol FF and EDTA $20 \mathrm{mM}$ ), denatured at $95^{\circ} \mathrm{C}$ for $5 \mathrm{~min}$, and immediately plunged into ice. Each PCR product was loaded into the $1 \mathrm{~mm}$-thick gel 0.5X MDE® (Cambrex, Rockland ME, USA), $1 \mathrm{X}$ TBE (0.045 M Tris/borate, $1 \mathrm{mM}$ EDTA) and run at $15^{\circ} \mathrm{C}, 8 \mathrm{~W}, 300 \mathrm{~V}$ for $4 \mathrm{~h}$. PCR and SSCP conditions were performed as described by Kjøller and Rosendahl (2000) and by Rosendahl and Stukenbrock

\section{AMF native spores abundance from soybean crops}

AMF spores were extracted from $50 \mathrm{~g}$ of each field soil treatment by wet sieving, decantation of $60 \%$ sucrose gradient centrifugation and collection of the spores and soil particles in $53 \mu \mathrm{M}$ sieves as described by Sieverding (1991). Isolated spores were surface cleaned by sonication (Quantrex S200 Sweep Zone (TM) Technology L \& R kit), and surface sterilized with a solution of $5 \mathrm{mg} / \mathrm{L}$ streptomycin sulphate and neomycin sulphate at 25 $\mu \mathrm{L} /$ sample three times for 5 minutes (according to a modification of the protocols by Covacevich and Consolo, 2014).

The total number of AMF spores (clean and healthy spores, in which internal nuclei were evident) in each sample was quantified under a binocular magnifying glass (6 X magnification) and referred to $100 \mathrm{~g}$ of soil. The spores were transferred to $1.5 \mathrm{~mL}$ eppendorf ${ }^{\circledR}$ tubes with $100 \mu \mathrm{L}$ of sterile distilled water and were multiplied.

AMF spores were morphologically identified by optical microscopy using the taxonomic system proposed by Schußler and Walker (2010), by comparisons with the descriptions of species published on the website of the International Culture Collection of Vesicular Arbuscular Mycorrhizal Fungi (INVAM, http: / /invam.caf.wvu.edu/) 
and AMF material from Spegazzini Institute (La Plata, Argentina).

\section{AMF spores multiplication in trap cultures}

Isolated spores of each treatment were multiplied during 9 weeks in a growth chamber, with a mix $(50 \% \mathrm{~V} / \mathrm{V})$ of $10 \mathrm{~g}$ of ryegrass and clover as trap-plants, which were seeded in $1 \mathrm{~kg}$ pots. Pots were filled with a mixture of soil (from the field experiment fumigated with formaldehyde following Covacevich and Echeverría (2003): perlite: sand (autoclaved) 1:1:1 in vol. After 9 weeks roots were separated from the substrate, washed and stained with a trypan blue $(0.05 \%)$ in distilled water-acid lactic-glycerol (1:1:1 in vol) solution according to the modification of Phillips and Hayman (1970) method, in which the phenol reagent was omitted. Arbuscular mycorrhizal colonization $(\mathrm{AMC})$, as well as the frequency of root infection, colonization intensity and arbuscule content, were quantified (Trouvelot et al., 1986).

\section{Trichoderma native abundance from soybean crops}

Trichoderma strains were isolated from $10 \mathrm{~g}$ of soil separately for each field treatment through the plate decimal dilution method on Agar-TSM (Trichoderma Selective Medium; Elad et al., 1981) and abundance (Unit Forming Colony $/ 100 \mathrm{~g}$ soil $)$ was quantified after growth $\left(28 \pm 0.5^{\circ} \mathrm{C}\right.$ for 7 - 10 days). Individual colonies were then separately transferred to Petri dishes with PDA (potato dextrose agar medium) and kept for 14 days at $25{ }^{\circ} \mathrm{C}$, which allowed for the multiplication of one isolated conidia (pure culture).

\section{Trichoderma molecular identification}

Genomic DNA from Trichoderma isolates was extracted from $100 \mathrm{mg}$ of mycelium from pure cultures based on Raeder and Broda (1985); DNA quality was checked on 1.5\%

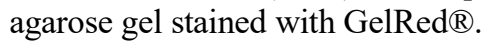

Polymerase chain reaction (PCR) that allowed for the amplification of internal transcribed spacers (ITS) of ribosomal DNA (rDNA) region from each Trichoderma isolate was performed with primers ITS1 (5TCCGTAGGTGAACCTGCGG-3) and ITS4 (5TCCTCCGCTTATTGATATGC-3) (White et al., 1990) which includes the ITS1, the 5.8S rDNA gene and the ITS2 regions. PCR was conducted in a mixture containing $10 \mathrm{ng}$ of genomic DNA, $20 \mathrm{mM}$ Tris- $\mathrm{HCl}(\mathrm{pH} 8.4), 50 \mathrm{mM} \mathrm{KCl}, 1.5$ $\mathrm{mM} \mathrm{MgCl} 2,0.2 \mathrm{mM}$ each of the four dNTPs, $0.5 \mathrm{mM}$ of each primer, and 1 unit of Taq polymerase (Promega WI, USA). Thermal cycling conditions involved an initial denaturation step at $94{ }^{\circ} \mathrm{C}$ for $2.5 \mathrm{~min}$, followed by 40 cycles of $94{ }^{\circ} \mathrm{C}$ for $15 \mathrm{~s}, 48^{\circ} \mathrm{C}$ for $1 \mathrm{~min}$ and $72{ }^{\circ} \mathrm{C}$ for $1.5 \mathrm{~min}$, and a final extension at $72{ }^{\circ} \mathrm{C}$ for $10 \mathrm{~min}$. PCR products were separated by electrophoresis in a $1 \%$ agarose gel mixing with GelRed $\AA$ (Genbiotech, UK) during $1 \mathrm{~h}$ at $120 \mathrm{~V}$. The expected size and the quality of the amplicons were checked on $1 \%$ agarose gel. PCR amplification products were purified and sequenced by Macrogen (Korea) using the ITS4 primer.

\section{Trichoderma and AMF inoculation: Effect on tomato plant growth}

In a tomato pot experiment, Trichoderma and AMF strains selected by their diversity and/or proliferation ability were inoculated, both alone and in combination, to test their ability to promote plant growth. The experimental design was randomized in blocks with 7 treatments and four replicates as detailed: 1) Uninoculated (Control); 2) Inoculated with AMF consortium from the field plot W-rot (AMF W-rot); 3) inoculated with $\mathrm{AMF}$ consortium from the field plot $\mathrm{CC} / \mathrm{Sb}$ (AMF CC/Sb); 4) inoculated with Trichoderma from the field plot W rot (Tch W-rot); 5) Inoculated with Trichoderma from the field plot $\mathrm{CC}(\mathrm{Tch} \mathrm{CC} / \mathrm{Sb}) ; 6)$ inoculated with consortium with AMF and Trichoderma from the field plot W-rot (AMF+Tch W-rot); 7) inoculated with consortium with AMF and Trichoderma from the field plot $\mathrm{CC} / \mathrm{Sb}$ (AMF+Tch $\mathrm{CC} / \mathrm{Sb})$.

Certified tomato seeds (Solanum lycopersicum, "platense" cv.) were surface sterilized with $10 \%$ sodium hypochlorite for $1 \mathrm{~min}$ followed by $10 \%$ alcohol for $1 \mathrm{~min}$, rinsed with sterile distilled water and kept in Petri dishes with distilled sterile water for $24 \mathrm{~h}$, facilitating the hydration of seeds.

Tomato seed inoculation was separately done for each selected Trichoderma strain. Seeds were shaken for $30 \mathrm{~min}$ with a magnetic stirrer in an Erlenmeyer flask containing 90 $\mathrm{mL}$ of $5 \%$ Agar-water plus $10 \mathrm{~mL}$ of an aqueous suspension Trichoderma strains that was adjusted to $1 \times 10^{8}$ conidia $/ \mathrm{mL}$ and a drop of surfactant (Tween 20). For control treatment, the same procedure was performed in the absence of conidia (mock inocula). Treated seeds were dried on a sterile absorbent paper for $24 \mathrm{~h}$ at room temperature and then placed in a moist chamber for germination for 7 days at room temperature.

Two pre-germinated seeds were planted in $500 \mathrm{~mL}$ pots filled with a substrate composed of non-sterilized agricultural soil $(0-20 \mathrm{~cm})$ form the field experiment mixed with sterile sand and perlite (2:1:1 soil: sand: perlite $\mathrm{w} / \mathrm{v})$. Tomato plants were grown in a plant growth chamber $(25$ ${ }^{\circ} \mathrm{C}, 12 \mathrm{~h}$ light/12 h dark) for 45 days and watered every 72 h. After 15 days, one plant per pot was removed.

At sowing and at 10 days after sowing (DAS) tomato roots were inoculated with $2 \mathrm{~mL} /$ pot aqueous suspension 
containing 12 AMF spores of selected treatments (AMF Wrot and $\mathrm{AMF} \mathrm{CC} / \mathrm{Sb}$ ); spores consisted of a homogeneous mixture of genus Acaulospora, Rhizophagus, Funneliformis decimal dilutions were made. Two hundred microliters of 10-1 and 10-2 dilutions were distributed in Petri dishes with Agar-TSM medium (Elad et al., 1981), which were

Table 2: Genetic AMF diversity (PCR-SSCP) and AMF and Trichoderma abundance at field experiment

\begin{tabular}{lllc}
\hline Field Experiment Treatments & $\begin{array}{l}\text { AMF spores abundance } \\
\text { (No } \text { spores/100 g soil) }\end{array}$ & $\begin{array}{l}\text { Genetic AMF Diversity Index } \\
\left(\mathbf{H}^{\prime}\right)\end{array}$ & $\begin{array}{l}\text { Trichoderma abundance } \\
\text { (CFU/100 g dry soil) }\end{array}$ \\
\hline $\mathrm{Sb}$ & $218 \mathrm{~b}$ & 1.4 & $6.2 \times 10^{3} \mathrm{~b}$ \\
$\mathrm{CC} / \mathrm{Sb}$ & $266 \mathrm{~b}$ & 2.0 & $5.2 \times 10^{3} \mathrm{~b}$ \\
$\mathrm{M}-\mathrm{rot}$ & $476 \mathrm{a}$ & 1.7 & $5.8 \times 10^{3} \mathrm{~b}$ \\
$\mathrm{~W}-\mathrm{rot}$ & $220 \mathrm{~b}$ & 2.1 & $2.6 \times 10^{4} \mathrm{a}$ \\
$\mathrm{CC} / \mathrm{Sb}-$-rot & $254 \mathrm{~b}$ & 1.7 & $4.0 \times 10^{3} \mathrm{~b}$ \\
\hline
\end{tabular}

Values in columns with same letters show no significant differences among treatments $(p<0.05)$

and Claroideoglomus (according to the INVAM classification, http://invam.wvu.edu/). Non-inoculated soil pots received a $2 \mathrm{~mL}$ of mock inocula (Schroeder and Janos, 2004) which consisted of a filtrate of soil of selected treatments $(40 \mathrm{~g}$ of soil shaken for $1 \mathrm{~h}$ in $400 \mathrm{~mL}$ of sterile deionized water filtered in Whatman No. 1).

\section{Plant growth and microbial determinations in a pot experiment}

Tomato plants height and SPAD units (average 3 lectures per plant using a SPAD MINOLTA 502) were measured at 45 DAS. Shoots were cut and shoot fresh weight (SFW) was recorded. Leaf images were captured and leaf area was calculated by using the ImageJ program (https://imagej.nih.gov/ij/). Shoot dry weight (SDW) was determined after drying shoots and the leaves $\left(60{ }^{\circ} \mathrm{C}\right.$ for 72 h). Roots were separated from the substrate, fully recovered, washed, dried with absorbent paper, and root fresh weight (RFW) was measured.

Inoculation responsiveness (IR) was separately calculated according to Cavagnaro et al. (2003) for each inoculation treatment according to the following equation (Eq. 2):

$\mathrm{Eq}(2)$

$$
I R=\frac{S D W(I)-\text { mean } S D W(N I)}{\text { mean } S D W(N I)} \times 100
$$

where SDW is the individual SDW production of inoculated (I) plants and mean SDW of NI (control) plants. The IR was similarly calculated for SFW and for RFW.

After RFW quantification, roots were stained and AMC was quantified as detailed above (2.4 section). At the end of the pot experiment, abundance of Trichoderma in the pots substrate was assessed as described: $10 \mathrm{~g}$ of substrate of each pot was weighed and suspended in $90 \mathrm{~mL}$ of sterile distilled water; the solution was homogenized on a horizontal stirrer at $150 \mathrm{rpm}$ for $25 \mathrm{~min}$. and four serial incubated as described above for the isolation of species of the genus Trichoderma (2.5 section). Counts of Colony Forming Units (CFU) of Trichoderma were recorded (Covacevich and Consolo, 2014).

\section{Statistical analysis}

Tested variables were analyzed using an analysis of variance (ANOVA); means were separated by the Tukey's test $(p<0.05)$ by using the SAS software (2005).

\section{Results and Discussion}

\section{AMF and Trichoderma indigenous selection from soybean systems with potential to promote plants growth}

AMF and Trichoderma indigenous strains selection from different soybean crop systems was based on their diversity and ability to proliferate in different crop systems. High genetic diversity ( $\left.\mathrm{H}^{\prime}\right)$ of AMF belonging to the genus Glomus and Funneliformis (Glomerales order) quantified through the PCR-SSCP strategy was obtained in W-rot system, followed by the $\mathrm{CC} / \mathrm{Sb}$ system, whereas the lowest $\mathrm{H}^{\prime}$ was obtained in the $\mathrm{Sb}$ monoculture system (Table 2). Highest abundance of AMF spores was found in the M-rot system, which almost doubled the abundance recorded in other treatments. Highest abundance of Trichoderma was recorded in the W-rot system. Our results clearly show that different soybean management systems modified the abundance of both studied fungi. Particularly, the inclusion of oat in rotations (CC/Sb-rot) increased the abundance of both fungal groups as well as the diversity of indigenous Glomerales of soybean crops.

The infective ability of native AMF propagules from different soybean crop systems was evaluated through Arbuscular Mycorrhizal Colonization (AMC) in trap culture. Highest infective capacity was found in trap culture with substrates from the $\mathrm{CC} / \mathrm{Sb}$ and $\mathrm{W}$-rot systems in which an $\mathrm{AMC}$ of $73 \%$ and $69 \%$ was reached, respectively. These 
degrees of colonization significantly exceeded those obtained in M-rot and $\mathrm{CC} / \mathrm{Sb}$-rot rotations $(51 \%$ and $47 \%$, respectively), while the lowest $\mathrm{AMC}$ was found in the trap culture from $\mathrm{Sb}$ monoculture system (29\%).

Trichoderma isolates from all soybean cultivation systems showed abundant proliferation in culture medium. However, Trichoderma isolates from the $\mathrm{CC} / \mathrm{Sb}$ and $\mathrm{W}$-rot systems showed fast conidia proliferation at $72 \mathrm{~h}$ of growth, as compared to isolates from the other systems.

Highest AMF diversity and infective capacity as well as the highest production of Trichoderma conidia found in the $\mathrm{CC} / \mathrm{Sb}$ and $\mathrm{W}$-rot systems suggest that native fungi of these systems would have better potential as promoters of plant growth, as compared to other evaluated systems.

Trichoderma species from treatments W-rot and $\mathrm{CC} / \mathrm{Sb}$ were genetically identified as Trichoderma tomentosum and

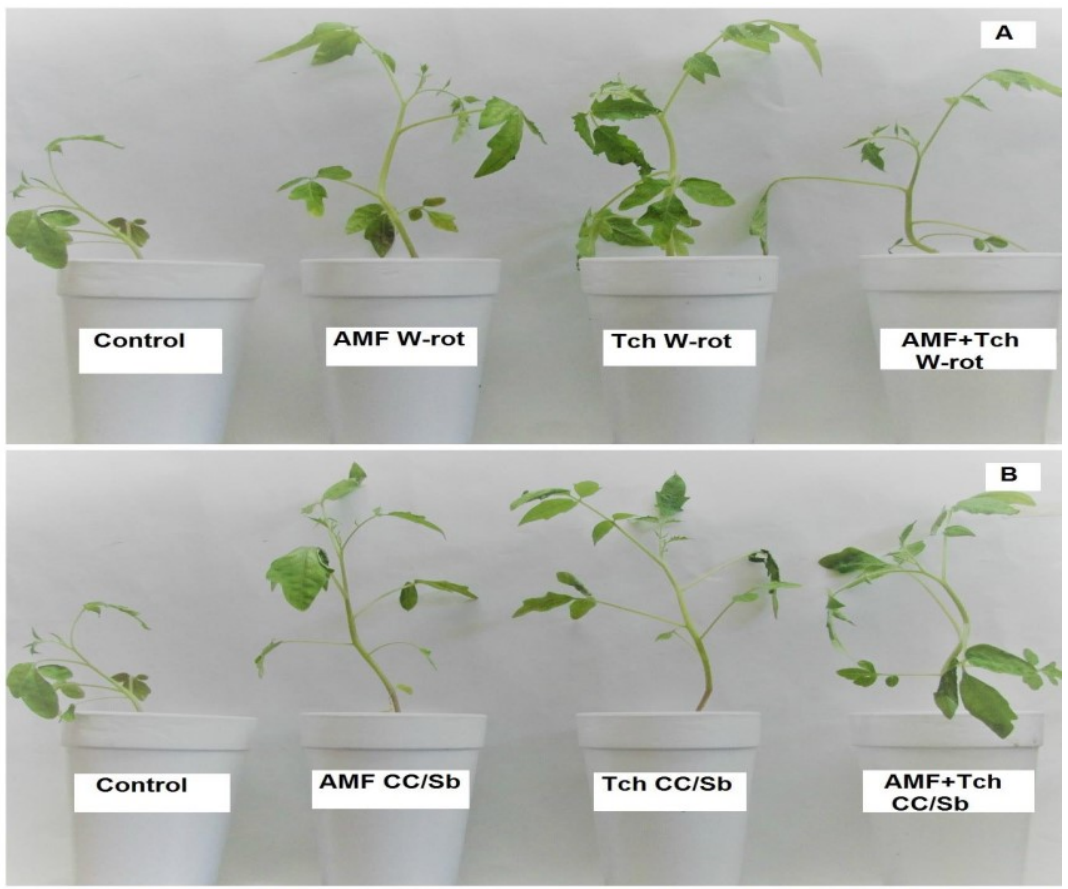

Figure 1: Tomato plants growth after 45 days. A: (from left to right) without inoculation (control), inoculated with AMF W-rot, Tch W-rot and inoculated with both fungi (AMF+Tch W-rot). B: (from left to right) without inoculation (control), inoculated with $\mathrm{AMF} \mathrm{CC} / \mathrm{Sb}$, Tch $\mathrm{CC} / \mathrm{Sb}$ and inoculated with both fungi (AMF+Tch $\mathbf{C C} / \mathbf{S b})$

Table 3: Growth parameters in tomato plants (45 DAS) as affected by single or dual inoculation with arbuscular mycorrhizal consortium (AMF) or Trichoderma (Tch) indigenous strains from soybean crops. $\mathrm{CC} / \mathrm{Sb}$ : Soybean after oat as cover crop-CC- ; W-rot: systems including rotations (rot) of crops with the three phases of rotation in different plots (CC/Soybean-Maize-Wheat) with wheat (W-rot) in the year of study; SFW: shoot fresh weight; SDW: shoot dry weight; RFW: root fresh weight; CFU: colony forming units

\begin{tabular}{|c|c|c|c|c|c|c|c|}
\hline Treatments & $\begin{array}{l}\text { Shoot height } \\
\text { (cm) }\end{array}$ & $\begin{array}{l}\text { Greenness } \\
\text { Index (SPAD) }\end{array}$ & SFW (g) & SDW (g) & RFW (g) & $\begin{array}{l}\text { Leaf area } \\
\left(\mathrm{cm}^{2}\right)\end{array}$ & $\begin{array}{l}\text { Trichoderma abundance } \\
\text { (CFU g } \text { g }^{-1} \text { dry soil) }\end{array}$ \\
\hline Control & $10.25 \mathrm{~d}$ & $29 \mathrm{a}$ & $0.86 \mathrm{~b}$ & $0.06 \mathrm{~b}$ & $0.15 \mathrm{~b}$ & $0.63 \mathrm{~d}$ & $417.0 \mathrm{~d}$ \\
\hline AMF W-rot & $17.01 \mathrm{a}$ & $30 \mathrm{a}$ & $1.96 \mathrm{a}$ & $0.15 \mathrm{a}$ & $0.36 \mathrm{ab}$ & $1.45 \mathrm{~b}$ & $1423.7 \mathrm{c}$ \\
\hline AMF CC/Sb & $17.02 \mathrm{a}$ & $30 \mathrm{a}$ & $1.82 \mathrm{a}$ & $0.13 \mathrm{a}$ & $0.22 \mathrm{~b}$ & $0.96 \mathrm{~cd}$ & $1527.7 \mathrm{c}$ \\
\hline Tch W-rot & $14.75 \mathrm{bc}$ & $30 \mathrm{a}$ & $1.55 \mathrm{ab}$ & $0.11 \mathrm{ab}$ & $0.50 \mathrm{a}$ & $1.09 \mathrm{c}$ & $3611.0 \mathrm{a}$ \\
\hline Tch CC/Sb & $16.51 \mathrm{ab}$ & $31 \mathrm{a}$ & $1.55 \mathrm{ab}$ & $0.14 \mathrm{a}$ & $0.37 \mathrm{ab}$ & $2.16 \mathrm{a}$ & $4097.3 \mathrm{a}$ \\
\hline AMF+Tch W-rot & $14.25 \mathrm{c}$ & $33 \mathrm{a}$ & $1.49 \mathrm{ab}$ & $0.10 \mathrm{ab}$ & $0.59 \mathrm{a}$ & $1.06 \mathrm{c}$ & $2569.3 \mathrm{~b}$ \\
\hline AMF+Tch $\mathbf{C C} / \mathbf{S b}$ & $14.25 \mathrm{c}$ & $31 \mathrm{a}$ & $1.66 \mathrm{a}$ & $0.11 \mathrm{ab}$ & $0.37 \mathrm{ab}$ & $1.25 \mathrm{bc}$ & $2465.0 \mathrm{~b}$ \\
\hline
\end{tabular}
Different letters in columns indicate significant differences among treatments (Tuckey, $p<0.05$ ). 
T. harzianum, respectively. Sequences of ITS-rDNA regions were deposited in the GenBank (https://www.ncbi.nlm.nih.gov/) under the accession numbers MG737695 and MG737696 (available online

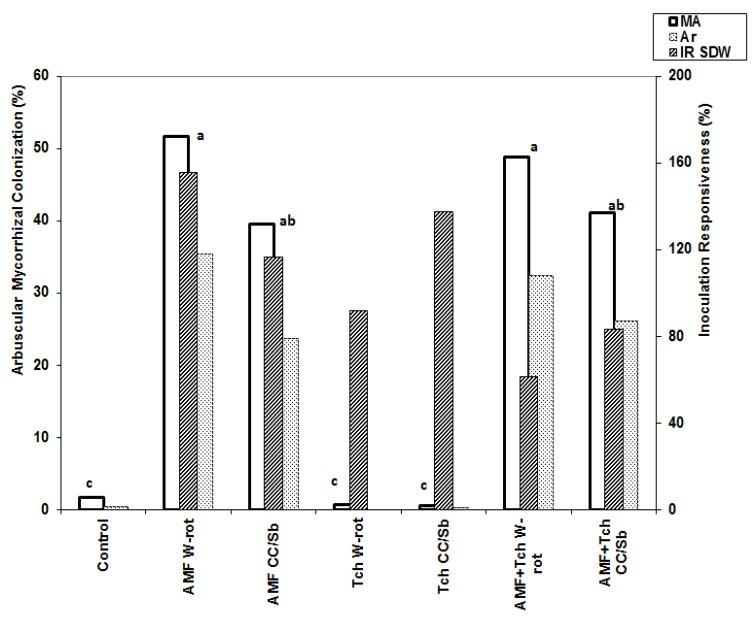

Figure 2: Arbuscular mycorrhizal colonization in tomato roots quantified as mycorrhizal intensity (MA) and Arbuscule content (Ar). Inoculation responsiveness in shoot dry weight (IR SDW) of inoculated plants relative to control

Control $=$ not inoculated; $\mathrm{AMF}$ W-rot: Inoculated with AMF consortium from the field treatment $\mathrm{W}$-rot; $\mathrm{AMF} \mathrm{CC} / \mathrm{Sb}$ : Inoculated with $\mathrm{AMF}$ consortium from the field $\mathrm{CC} / \mathrm{Sb}$ treatment; Tch W-rot: Inoculated with Trichoderma from the field treatment W-rot; Tch CC/Sb: Trichoderma inoculated from the field $\mathrm{CC} / \mathrm{Sb}$ treatment; AMF+Tch W-rot: Inoculated with consortium with AMF and Trichoderma from the treatment field W-rot; $\mathrm{AMF}+\mathrm{Tch} \mathrm{CC} / \mathrm{Sb}$ : Inoculated with consortium with $\mathrm{AMF}$ and Trichoderma from the field $\mathrm{CC} / \mathrm{Sb}$ treatment.

Columns with different letters indicate significant differences in mycorrhizal colonization among inoculation treatments (Tuckey, $p<0.05)$. Statistical analysis results were similar for MA and Ar.

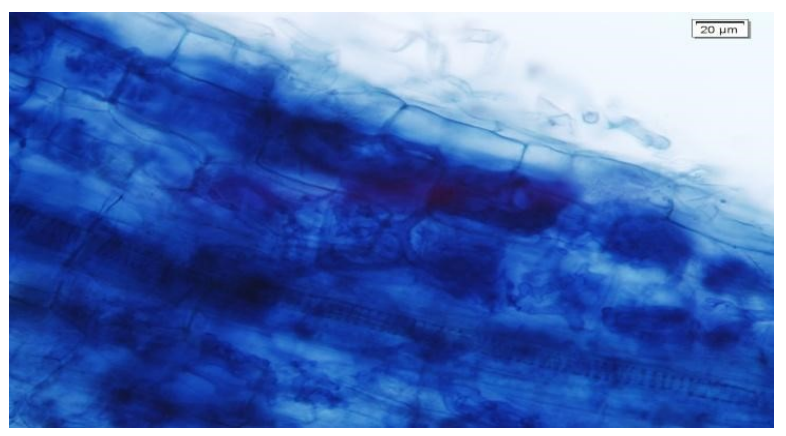

Figure 3: Mycorrhizal colonization of tomato roots after inoculation with arbuscular mycorrhizal fungi (40x magnification)
https://blast.ncbi.nlm.nih.gov/Blast.cgi). Mycorrhizal fungi were morphologically identified as belonging to the Acaulospora, Rhizophagus, Funneliformis and Claroideoglomus genus.

\section{Tomato growth response to single and dual inoculation with selected AMF and Trichoderma indigenous from soybean crops}

Significant increases in SDW, SFW, RFW and leaf area of tomato plants at 45 DAS were found as a result of single and/or dual inoculation with AMF-Trichoderma (Figure 1), as compared to the Control (Table 3). Similarly, Bader et al. (2019) showed increases up to $300 \%$ in tomato plants growth inoculated with $T$. harzianum indigenous from Argentina. Our results showed that inoculation responses (IR) were always positive, with a marked increase (above 60\%) resulting from inoculation with Trichoderma strains. Higher IR-SDW (above 140\%) was found after single inoculation with $T$. harzianum indigenous from $\mathrm{CC} / \mathrm{Sb}$ system of Argentina soybean fields, as compared to the Control (Figure 2). Bal and Altinatas (2008) reported that lettuce plants (Lactuca sativa) inoculation with $T$. harzianum increased only seedling fresh weight, without increasing roots weight. A higher IRRFW (above 244\%) was obtained after single tomato inoculation with $T$. tomentosum indigenous from $\mathrm{W}$-rot system, as compared to the Control. To our knowledge, few studies have reported the effect of T. tomentosum inoculation on plant growth. Rabeendra et al. (2000) and Ousley et al. (1993) reported the efficiency of $T$. tomentosum on the growth of cabbage and lettuce plants, respectively.

Tomato growth increase due to AMF inoculation is well-known (Cavagnaro et al., 2007; Mujica Pérez and Fuentes Martínez (2012). Thougnon Islas et al. (2014) detected slight (not statistically significant) evidences on tomato plant growth promotion (IR up to $40 \%$ ) associated with an incipient colonization (23 DAS) by AMF indigenous from soybean monoculture systems of Argentinean Pampa. In our study, AMF indigenous from Wrot and $\mathrm{CC} / \mathrm{Sb}$ increased SDW above $110 \%$, as compared to the control. Our results suggest a growth promoting potential by Trichoderma and AMF from rotation systems and/or $\mathrm{CC} / \mathrm{Sb}$. We also obtained higher IR-SDW (above $60 \%$ ) after AMF and Trichoderma indigenous dual inoculation from rotation and/or with $\mathrm{CC} / \mathrm{Sb}$ systems, with respect to the control (Figure 2). We found tomato plant root growth (RFW) and shoot growth (SFW) increases when plants were inoculated with AMF+Tch W-rot (inoculum T. tomentosum consortium with $\mathrm{AMF}$ ) and $\mathrm{AMF}+\mathrm{Tch} \mathrm{CC} / \mathrm{Sb}$ (inoculum T. harzianum consortium with AMF), respectively (Table 3 ). The positive IR after dual 
inoculations found in our experiment is in agreement with some reports. Colla et al. (2015), for instance, reported that tomato plants inoculated with $G$. intraradices and $T$. atroviride, showed enhanced growth, as compared to control treatments. The increase in root and shoot weight was associated with an increase in nutrient uptake (e.g. $\mathrm{P}, \mathrm{Mg}$, $\mathrm{Fe}, \mathrm{Zn}$ and B). Martínez-Medina et al. (2011) reported growth increases after AMF and Trichoderma dual inoculation in melon crop (Cucumis melo L.). Similarly, Parkash et al. (2011) found that both AMF and Trichoderma viride single and dual inoculation had a positive effect on plant growth and root mycorrhizal colonization in Dendrocalamus strictus plants. Moreover, Dubsky et al. (2002) reported that AMF and T. harzianum dual inoculation increased growth of Cyclamen persicum and decreased plant mortality caused by spontaneous infection by Cryptocline cyclaminis fungal pathogen.

In this study, we found that highest Trichoderma abundance was recorded after single inoculation with Tch W-rot and also with Tch $\mathrm{CC} / \mathrm{Sb}$ (Table 3). Trichoderma abundance decreased in pot substrates that received dual inoculation (about 30-40\%, Table 3). In contrast, we found that AMC of tomato plants was not inhibited by Trichoderma since mycorrhizal colonization was higher than $40 \%$ in all AMF (single and also AMF+Trichoderma) inoculated plants (Figure 2); no differences in AMC were found between single and dual inoculation from the same crop system. Characteristic AMF arbuscules were found in inoculated tomato plant roots (Figure 3). Some studies showed positive (Datnoff et al., 1995) and neutral (Fracchia et al., 1998) interactions between T. harzianum and AMF species as Glomus intraradices and G. mosseae, respectively. However, detrimental effects of Trichoderma on mycorrhizal colonization were reported by Santander and Olave (2014), who found that Trichoderma depressed root mycorrhizal colonization of melon plants by $G$. intrarradices. In our study, a decrease in the population development of $T$. harzianum around the roots was found in the presence of AMF consortium, in agreement with prior findings (Sosa Rodríguez et al., 2006; Chandanie et al., 2009). It is unknown if the release of certain metabolites by the AMF can depress the development of Trichoderma. Future studies should deepen the knowledge of the mechanisms involved in the relations between both fungi in co-inoculation.

It is worth mentioning that some basal mycorrhizal colonization and low Trichoderma abundance were found even in non-inoculated treatments. We highlight that our results were promising since data were obtained from nonsterile soil conditions. Although the mechanisms and interactions of soil microorganisms are not well understood, it was suggested that soil microbiota could suppress the activity of introduced microorganisms by competition (Cook, 1991) and thus could depress inoculation responses. Results from our experiment have shown plant growth increases, AMF root colonization and Trichoderma abundance after inoculation, regardless of native microbiota. A possible advantage from non-sterile soil used in this experiment, would be that our results resemble field conditions.

In conclusion, we detected highest AMF abundance, Trichoderma and AMF diversity in alternative systems to soybean monoculture (such as the inclusion of oat as CC or rotation systems with wheat and maize). It is likely that the greater SOM provided either by the $\mathrm{CC}$ or by the crop rotation, has favored greater diversity of soil microbiota in general and AMF and Trichoderma in particular. Future studies should deepen the understanding of the factors of crop management practices that specifically favors the abundance and diversity of plant growth promoters microorganisms. Furthermore, both single and dual inoculation with native fungi from alternative systems to soybean monoculture would be important for horticultural crops because high inoculation responses were obtained. We suggest that root colonization prior to transplanting could provide root protection to pest and dryness, and improve tomato crop establishment under field conditions, in addition to decreasing production costs and environmental impacts.

\section{Conflicts of interest}

The authors declare no conflict of interest.

\section{Acknowledgments}

This work was supported by the Instituto Nacional de Tecnología Agropecuaria (INTA, Argentina Grants: E2 2019-PD-E2-I037-002; 2019-PE-E1-I011-001), Consejo Nacional de Investigaciones Científicas y Técnicas (CONICET, Argentina Grant PIP 0424), Universidad Nacional de Mar del Plata (Grant EXA925/19) and Agencia Nacional de Promocion Científica y Tecnológica (ANPCyT, Argentina Grant PICT 2015-0392). We thank M. Sc. Prof. Innocentini V.A. for the English correction of the manuscript.

\section{References}

Bader, A., F. Covacevich, G. Salerno and V.F. Consolo. 2019. Native Trichoderma harzianum strains from Argentina, produce indole- 3 acetic acid and phosphorus solubilization, promote growth and control wilt disease on tomato (Lycopersicum sculentum Mill.) Journal of 
King Saud University - Science DOI: https://doi.org/10.1016/j.jksus.2019.04.002

Bal, U. and S. Altintas. 2008. Effects of Trichoderma harzianum on lettuce in protected cultivation. Central European Agriculture Journal 9: 63-70.

Benbouza, H., J.M. Jacquemin, J.P. Baudoin and G. Mergeai. 2006. Optimization of a reliable, fast, cheap and sensitive silver staining method to detect SSR markers in polyacrylamide Gels. Biotechnologie, agronomie, société et environment 10: 77-81.

Cavagnaro, T.R., F.A. Smith, S.M. Ayling and S.E. Smith. 2003. Growth and P nutrition of a Paris-type arbuscular mycorrhizal symbiosis. New Phytologist 157: 127-134

Cavagnaro, T.R., S.K. Sokolow and L.E. Jackson. 2007. Mycorrhizal effects on growth and nutrition of tomato under elevated atmospheric carbon dioxide. Functional Plant Biology 34: 730-736.

Chandanie, W.A., M. Kubota and M. Hyakumachi. 2009. Interactions between the arbuscular mycorrhizal fungus Glomus mosseae and plant growth-promoting fungi and their significance for enhancing plant growth and suppressing damping-off of cucumber (Cucumis sativus L.). Applied Soil Ecology 41: 336-341.

Cho, G.D., M. Kim and W.W. Koo. 2004. The relative impact of national monetary policies and international exchange rate on long-term variations in relative agricultural prices. Center for Agricultural Policy and Trade Studies, Department of Agribusiness and Applied Economics, North Dakota State University, Fargo, North Dakota 58105-5636

Colla, G., Y. Rouphael, E. Di Mattia, C. El-Nakhel and M. Cardarelli. 2015. Co-inoculation of Glomus intraradices and Trichoderma atroviride acts as a biostimulant to promote growth, yield and nutrient uptake of vegetable crops. Journal of the Science of Food and Agriculture 95: 1706-1715.

Cook, J. 1991. A customized approach to biological control of wheat root diseases. p. 461. In: Biological Control of Plant Diseases: Progress and Challenges for the Future. Proceeding of a NATO Advanced Research Workshop on Biological Control of Plant Diseases. E.C. Tjamos, G.C. Papavizas and R.J. Cook (eds.). May, Greece Springer.

Covacevich, F. and H.E. Echeverría. 2003. Utilización de formaldehído para la erradicación de hongos micorríticos arbusculares de muestras de suelo. Ciencia del suelo. 21: 9-17.

Covacevich, F., H.E. Echeverría and M.C. Pagano. 2012. Arbuscular mycorrhizal fungi: Essential belowground organisms for earth life but sensitive to a changing environment. African Journal of Microbiology Research 6: 5523-5535.
Covacevich, F. and V.F. Consolo. 2014. Herramientas para el estudio y manipulación de Hongos Micorrícicos Arbusculares y Trichoderma. Universidad Nacional de Mar del Plata. $115 \mathrm{p}$.

Datnoff, L.E., S. Nemec and K. Pernezny. 1995. Biological control of Fusarium crown and root rot of tomato in Florida using Trichoderma harzianum and Glomus intraradices. Biological Control 5: 427-431.

Dubsky, M., F. Sramek and M. Vosatka. 2002. Inoculation of cyclamen (Cyclamen persicum) and poinsettia (Euphorbia pulcherrima) with arbuscular mycorrhizal fungi and Trichoderma harzianum. Rostlinna vyroba 48: 63-68.

Duval, M.E., J.A. Galantini, J.E. Capurro and J.M. Martinez. 2016. Winter cover crops in soybean monoculture: Effects on soil organic carbon and its fractions. Soil \& Tillage Research 161: 95-105.

Elad, Y., I. Chet and Y. Henis. 1981. A selective medium for improving qualitative isolation of Trichoderma spp. from soil. Phytoparasitica 9: 59-67.

Ene, M. and M. Alexandru. 2008. Microscopical examination of plant reaction in case of infection with Trichoderma and Mycorrhizal fungi. Roumanian Society of Biological Sciences 13: 13-19.

Fernández, R., A. Quiroga, F. Arena, C. Antonini and M. Saks. 2007. Contribución de los cultivos de cobertura y las napas freáticas a la conservación del agua, uso consuntivo y nutrición de los cultivos. Manual de Fertilidad y Evaluación de Suelos. EEA INTA Anguil, Argentina. 51: 59.

Fracchia, S., M.T. Mujica, I. García-Romera, J.M. GarciaGarrido, J. Martin, J.A. Ocampo and A. Godeas. 1998. Interactions between Glomus mosseae and arbuscular mycorrhizal sporocarp-associated saprophytic fungi. Plant and Soil 200: 131-137.

Guigón-López, C., V. Guerrero-Prieto, F. Vargas-Albores, E. Carvajal-Millán, G.D. Ávila-Quezada, L. Bravo-Luna and M. Lorito. 2010. Identificación molecular de cepas nativas de Trichoderma spp. su tasa de crecimiento in vitro y antagonismo contra hongos fitopatógenos. Revista mexicana de fitopatología 28: 87-96.

Gupta, M., N. Naqvi and P. Kumar. 2017. AMF-Centralized database of arbuscular mycorrhizal distribution, phylogeny and taxonomy. Journal of Recent Advances in Applied Sciences 30: 1-5.

Harman, G.E. 2006. Overview of mechanisms and uses of Trichoderma spp. Phytopathology 96: 190-194.

Kjøller, R. and S. Rosendahl. 2000. Detection of arbuscular mycorrhizal fungi (Glomales) in roots by nested PCR and SSCP (single stranded conformation polymorphism). Plant and Soil 226: 189-196. 
Kumar, K. and K.M. Goh. 2000. Biological nitrogen fixation, accumulation of soil nitrogen and nitrogen balance for white clover (Trifolium repens L.) and field pea (Pisum sativum L.) grown for seed. Field Crops Research 68: 49-59.

Marshall, C.B., J.R. McLaren and R. Turkington. 2011. Soil microbial communities resistant to changes in plant functional group composition. Soil Biology and Biochemistry 43: 78-85.

Martínez-Medina, A., A. Roldán and J.A. Pascual. 2011. Interaction between arbuscular mycorrhizal fungi and Trichoderma harzianum under conventional and low input fertilization field condition in melon crops: Growth response and Fusarium wilt biocontrol. Applied Soil Ecology 47: 98-105.

Mujica Pérez, Y. and A.G. Fuentes Martínez. 2012. Efecto a la biofertilización con hongos micorrízicos arbusculares (HMA) en el cultivo del tomate en condiciones de estrés abiótico. Cultivos tropicales 33: 40-46.

Ousley, M.A., J.M. Lynch and J.M. Whipps. 1993. Effect of Trichoderma on plant growth: A balance between inhibition and growth promotion. Microbial Ecology 26: 277-285.

Parkash, V., S. Sharma and A. Aggarwal. 2011. Symbiotic and synergistic efficacy of endomycorrhizae with Dendrocalamus strictus. L. Plant Soil and Environment 57: 447-52.

Phillips, J. and D. Hayman. 1970. Improved procedures for clearing roots and staining parasitic and vesiculararbuscular mycorrhizal fungi for rapid assessment of infection. Transactions of the British Mycological Society 55: 158-161.

Raeder, U. and P. Broda. 1985. Rapid preparation of DNA from filamentous fungi. Letters in Applied Microbiology 1: $17-20$.

Rabeendran, N., D.J. Moot, E.E. Jones and A. Stewart. 2000. Inconsistent growth promotion of cabbage and lettuce from Trichoderma isolates. New Zealand Plant Protection 53: 143-146.

Redecker, D., A. Schüßler, H. Stockinger, S. L. Stürmer, J. B. Morton and C. Walker. 2013. An evidence-based consensus for the classification of arbuscular mycorrhizal fungi (Glomeromycota). Mycorrhiza 23: 515-531.

Ritchie, S.W. and J.J. Hanway. 1982. How a corn plant develops. Iowa State University of Science and Technology. Cooperative Extension Service Ames, Iowa. Special Report No. 48.

Rillig, M.C., S.F. Wright and V.T. Eviner. 2002. The role of arbuscular mycorrhizal fungi and glomalin in soil aggregation: Comparing effects of five plant species. Plant and Soil 238: 325-33.
Rosendahl, S. and E. Stukenbrock. 2004. Community structure of arbuscular mycorrhizal fungi in undisturbed vegetation revealed by analyses of LSU rDNA sequences. Molecular Ecology 13: 3179-3186.

Santander, C. and J. Olave. 2014. Efecto de la interacción del hongo micorrícico arbuscular (AMF) Glomus intraradices y Trichoderma harzianum sobre la producción de plantines de melón en zonas áridas. Idesia (Arica) 32: 21-28.

SAS Institute. 2005. SAS User's Guide. Statistics. SAS Institute, Inc., Cary.

Schroeder, M.S. and D.P. Janos. 2004. Phosphorus and intraspecific density alter plant responses to arbuscular mycorrhizas. Plant and Soil 264: 335-348.

SchuBler, A. and C. Walker. 2010. The Glomeromycota. A species list with new families and new genera. The Royal Botanic Garden Kew, Botanische Staatssammlung Munich, and Oregon State University. Available at http://amfphylogeny.com/Schuessler\&Walker2010_Glomeromycota. pdf

Shannon, C.E. and W. Weaver. 1949. The mathematical theory of information. University of Illinois Press, Chicago USA.

Sharif, M., E. Ahmad, M.S. Sarir and S. Perveen. 2010. Response of different crops to arbuscular mycorrhizal inoculation in phosphorus deficient soil. Soil and Environment 29(2): 192-198.

Sidhoum, W. and Z. Fortas. 2018. Growth and mycorrhizal responses to cadmium stress in some halophytic plants. Soil and Environment 37(2): 169-177.

Sieverding, E. 1991. Vesicular arbuscular mycorrhizal management in tropical agroecosystems. Deutsche Gesellschsft fur Technische Zusammenarbeit (GTZ) tropics, Federal Republic of Germany. 371 p.

Solbrig, O.T. 2005. The dilemma of biodiversity conservation. Agricultural expansion in the Argentine Pampas. Harvard Review of Latin America, Flora and Fauna 3: 34-35.

Sosa Rodríguez, T., J. Sánchez Nieves, E. Morales Gutiérrez and F. Cruz Cortés. 2006. Interacción micorrizas arbusculares-Trichoderma harzianum (Moniliaceae) y efectos sobre el crecimiento de Brachiaria decumbens (Poaceae). Acta biológica colombiana 11: 43-54.

Tiunov, A.V. and S. Scheu. 2005. Arbuscular mycorrhiza and Collembola interact in affecting community composition of saprotrophic microfungi. Oecologia 142: 636-642.

Thougnon Islas, A.J., M. Eyherabide, H.E. Echeverría, H.R. Sainz Rozas and F. Covacevich. 2014. Capacidad micotrófica y eficiencia de consorcios con hongos micorrízicos nativos de suelos de la provincia de Buenos Aires con manejo contrastante. Revista Argentina de Microbiología 46: 133-143. 
Trouvelot, A. 1986. Mesure du taux de mycorhization VA d'un systeme radiculaire. Recherche de methodes d'estimation ayant une significantion fonctionnelle. Mycorrhizae: Physiology and Genetics 217-221.

Van Elsas, J.D., M. Chiurazzi, C.A. Mallon, D. Elhottovā, V. Krišstůfek and J. Falcão Salles. 2012. Microbial diversity determines the invasion of soil by a bacterial pathogen. Proceedings of the National Academy of Sciences 109: 1159-1164.

Van Tuinen, D., B. Zhao and V. Gianinazzi-Pearson. 1998. PCR in studies of AM fungi: From primers to application. p. 387-400. In Mycorrhiza manual. Springer Berlin Heidelberg.
Villamil, M.B., G.A. Bollero, R.G. Darmody, F.W. Simmons and D.G. Bullock. 2006. No-till corn/soybean systems including winter cover crops. Soil Science Society of America Journal 70: 1936-1944.

White, T.J., T.D. Bruns, S.B. Lee and J.W. Taylor. 1990. Amplification and direct sequencing of fungal ribosomal RNA genes for phylogenetics. p. 315-322. In: PCR Protocols: A Guide to Methods and Applications. M.A. Innis, D.H. Gelfand, J.J. Sninsky and T.J. White, (eds.), Academic Press, New York. 